\title{
DIFERENCIAS GENERACIONALES EN LA PARTICIPACIÓN electoral en Chile, 1988-2010*
}

\author{
Generational Differences in Electoral Participation in Chile, 1988-2010
}

\section{GONZALO CONTRERAS}

Universidad Diego Portales

\section{PATRICIO NAVIA}

Universidad Diego Portales

\begin{abstract}
RESUMEN
La participación electoral en Chile muestra una tendencia a la baja. En el plebiscito de 1988 votó el $90 \%$ de los mayores de 18 años, pero en la elección presidencial de 2009 solo lo hizo el 63\%. En los 22 años en que estuvo en vigencia el sistema de inscripción voluntaria y participación obligatoria, la caída en la participación no fue uniforme. En 2010, la tasa de inscripción en comunas de altos ingresos, como Providencia y Las Condes era de $97,1 \%$ y $69,9 \%$, respectivamente; mientras que en comunas populares como Maipú y Puente Alto alcanzaba a 30,3\% y 29\% de los mayores de 18 años, respectivamente. Abordamos el debate sobre la participación electoral a partir de una discusión teórica que da cuenta de las razones que inducen a la gente a votar. Luego analizamos la evolución de la participación electoral tanto en el periodo anterior a 1973 como post-1990. Con datos de inscripción electoral y de encuestas evaluamos las características sociodemográficas de los inscritos, de los que votan y de los no inscritos. Hasta la reforma que hizo la inscripción automática y el voto voluntario, el universo electoral crecientemente representaba solo los sectores de mayores ingresos. Advertimos que la decreciente participación electoral en Chile se explica por diferencias generacionales en procesos de socialización política, por lo que los efectos de la reforma de la voluntariedad del voto pudieran no producir un aumento uniforme en la participación electoral.
\end{abstract}

Palabras clave: Participación electoral, desarrollo político chileno, diferencias generacionales, determinantes del voto, votación obligatoria

\begin{abstract}
Chile is experiencing a declining electoral participation. In the 1988 plebiscite, $90 \%$ of those aged 18 or older voted. In the 2009, only $64 \%$ went to the polls. In the 22 years that Chile had a system of voluntary registration and mandatory voting, the decline in electoral participation was not uniform across social groups. In 2010, electoral registration rates among voting age persons in the high income municipalities of Providencia and Las Condes were $97.1 \%$ and $69.9 \%$ respectively, while in low income municipalities like Maipú and Puente Alto only
\end{abstract}

* $\quad$ Este trabajo contó con apoyo del Proyecto Fondecyt 1120638 ("How have electoral preferences, institutional incentives and internal party/coalition politics determined who wins and who loses in legislative and municipal elections in Chile, 1989-2009"). Agradecemos a los árbitros anónimos de la RCP y a nuestros colegas del Observatorio Político Electoral UDP por sus comentarios y sugerencias. Los errores y omisiones son de nuestra responsabilidad. 
$30.3 \%$ and $29 \%$ respectively of the voting age population was registered. Starting from the theoretical discussion on the determinants of turnout, we analyze the current debate on electoral participation and the historical evidence on pre 1973 turnout rates and electoral participation after 1989. Using electoral registration data and polls, we analyze the differences between those Chileans registered to vote and those not enfranchised. Until the reform that automatized registration and implemented voluntary voting, the voting population increasingly over represented high income voters. Because decreasing electoral participation can be explained by generational differences in socialization processes, the effects of voluntary voting might end up producing a non-uniform change in electoral participation.

Key words: Electoral Participation, turnout, vote determinants, mandatory voting, generational differences.

En la elección presidencial de 2009 en Chile solo el 63\% de la población en edad de $\operatorname{votar}(\mathrm{PEV})$-aquellos mayores de 18 años- participó del proceso y solo el 56,7\% emitió votos válidos. Veintiún años antes, en el plebiscito de 1988, el 90\% había emitido votos.

Durante los años en que estuvo en vigencia el sistema de inscripción voluntaria y votación obligatoria se produjo un declive no uniforme en la participación electoral. En 2009, en Maipú, la comuna más poblada del país, solo el 30,3\% de la PEV estaba inscrita. En Vitacura, la comuna con más altos ingresos, la tasa de inscripción alcanzaba al 97,3\% de la PEV. En 2010 la tasa de inscripción en comunas de altos ingresos como Providencia y Las Condes era de $97,1 \%$ y $69,9 \%$, respectivamente, mientras que en la populosa comuna de clase media baja de Puente Alto alcanzaba a 29\%. Después de reformas que establecieron la automaticidad de la inscripción electoral y la voluntariedad del voto, todos los chilenos están inscritos para votar. Pero ¿volveremos a los altos niveles de participación observados durante la transición a la democracia? Después de una discusión teórica que da cuenta de las razones que inducen a la gente a votar-incluyendo argumentos a favor y en contra de la voluntariedad del sufragio- analizamos la evolución histórica de la participación electoral en Chile. A partir de datos de inscripción electoral y usando encuestas nacionales, evaluamos las características sociodemográficas del electorado que votaba y de aquellos que recientemente se han incorporado al padrón de forma automática. Concluimos mostrando que hasta la reciente reforma el universo electoral crecientemente representaba solo los sectores de mayores ingresos.

\section{I. ¿POR QUÉ VOTA LA GENTE?}

El teorema del votante mediano sugiere que en una elección a dos bandas, para maximizar la posibilidad de ganar, ambos candidatos proponen políticas que reflejan la preferencia del votante más moderado (Downs, 1957; 2001). Ante opciones idénticas, el votante mediano es indiferente, por lo que ambos candidatos tienen igual posibilidad de triunfo. En este modelo, la participación es obligatoria. Pero cuando la votación es voluntaria, ¿por qué molestarse en escoger entre dos candidatos que ofrecen lo mismo? Peor aún, ¿por qué alguien participaría en un proceso electoral donde su probabilidad de influir en el resultado es mínima? 
Riker y Odershook (1968) entienden esta paradoja de la participación como una función de utilidad que incluye los beneficios de votar, la probabilidad que el voto sea decisivo y los beneficios que implica la victoria del candidato favorito (Uhlaner, 1995: 69). La decisión de votar depende de las políticas a ser adoptadas, del costo de votar y de la probabilidad de ser el elector decisivo (reconocida como baja). Aunque las políticas propuestas por ambos candidatos son similares, los beneficios esperados de esas políticas varían poco. Por eso, un valor marginalmente alto del costo de votar redundará en altos niveles de abstención.

Downs supuso que los votantes saben que la salud de la democracia depende de que mucha gente vote y que por lo tanto están dispuestos a incurrir en los costos que implica votar (1995: 67). Pero, como es usual con los bienes públicos, su provisión presenta un problema de acción colectiva. Los ciudadanos adoptan posturas de free riders y se abstienen, obteniendo el beneficio de la democracia sin pagar su costo (Aldrich, 1993: 48). Ahora bien, la gente votará si teme que una baja participación debilite la democracia (Aldrich, 1993: 248). Además, incapaces de anticipar el comportamiento de otros votantes, los electores no saben si su voto será decisivo (Ferejohn and Fiorina, 1974: 527). Pero Aldrich también argumenta que "la participación electoral es una acción de bajo costo y bajo beneficio" (1993: 261). Una participación alta no sería incompatible con un comportamiento racional. Cuando la votación es obligatoria, la paradoja de la participación no desaparece. Se puede anular o votar en blanco. La participación electoral implica un nivel de racionalidad más sofisticado que una consideración exclusiva de costos y beneficios económicos. Por eso, aunque fuera voluntaria, la tasa de participación será sustancialmente superior a cero. De ahí que las razones que a menudo se esgrimen para defender la obligatoriedad o voluntariedad del voto sean de carácter normativo más que racional.

No solo importa saber qué porcentaje del electorado vota, sino también si el universo de votantes es una muestra representativa de la PEV. Ciertos grupos participan más (Ferejohn y Fiorina, 1974; Powell Jr., 1986) y hay relación entre valores culturales y participación política (Almond y Verba, 1963). En culturas participativas, los ciudadanos están más satisfechos con sus instituciones y son más eficaces políticamente (Jackman y Miller, 1995: 468).

La participación también está relacionada con el contexto competitivo de elecciones, factores institucionales, y con los niveles de educación y grupos etáreos (Powell, 1986: 21). Grofman recuerda que "ceteris paribus, la participación electoral es menor cuando el clima no es bueno, cuando las barreras de inscripción electoral son más altas y cuando a poca gente le preocupa el resultado de la elección" (1995: 102). El diseño institucional también afecta la participación, y cambios relativamente menores pueden afectar el número de gente que vota (Jackman and Miller, 1995; Lijphart, 1997; Powell Jr., 1986).

Para expandir el universo electoral Lijphart propuso "medidas que mejoren la estructura institucional del país en vez de aumentar los niveles de educación de la población o buscar temas que pudieran interesar electoralmente más a los votantes" (1997: 7). De hecho, la variable de predicción más poderosa de la participación es la inscripción 
automática (Powell, 1986: 25). Disminuir las barreras de entrada para la incorporación al padrón tiene un efecto superior al que pudiera generar eliminar el voto obligatorio. En Chile, bien pudiera ser que la baja participación se asociara con las barreras de entrada que dificultaban la incorporación al padrón electoral. De hecho, el cambio a un sistema de inscripción automática buscó enmendar los problemas de participación. Pero, como discutimos más adelante, la efectividad de esta medida es cuestionable si no se considera en conjunto con la obligatoriedad del voto.

Sistemas multipartidistas producirían una mayor participación, ya que, al haber una mayor cantidad de opciones, los votantes tienen más posibilidades para elegir, lo que aumentaría su probabilidad de votar. Sin embargo, hay evidencia de que la representación proporcional (RP) disminuye la participación (Blais y Carthy, 1990; Franklin 1996; 2004; Jackman, 1987; Powell Jr., 1986), cuestión que también parece ser cierta en América latina (Fornos, Power, and Garand, 2004; Pérez-Liñán, 2001). Franklin (2004) plantea que, en un sistema de RP, las personas tienen menos probabilidades de votar, ya que sienten que su voto no será decisivo. Además, el costo de informarse sobre las diferentes alternativas jugaría en contra de la participación. Blais argumenta, además, que "un sistema multipartidista usualmente conlleva a la formación de coaliciones políticas, lo que provocaría que las elecciones fueran menos decisivas debido a que la composición final de dichas coaliciones depende de la coordinación que los partidos lleven a cabo" (Blais, 2008: 628). Sin embargo, no se puede aseverar de manera categórica que el tipo de sistema electoral tenga un impacto sobre la participación (Blais, 2008).

Por otro lado, la importancia, o el tipo de elección, estaría directamente relacionada con el nivel de votación (Blais, 2008). En sistemas presidenciales adquirirán mayor importancia las elecciones presidenciales. De hecho, para el caso latinoamericano, luego de las transiciones democráticas de varios países durante la década de los 80, se registraron altos niveles de votación. En el plebiscito de 1988 en Chile el nivel de votación rondó el 90\% (Navia, 2004).

Las barreras de entrada -el costo que significa acudir a las urnas- también deprimen la participación (Blais, Massicotte, y Dobrzynska, 2003; Franklin, 1996; Highton, 1997; Mitchell y Wlezien, 1995; Norris, 2004). La participación aumenta cuando el proceso es más fácil (Blais, 2008), aunque se mantendría inalterable la composición sociodemográfica y socioeconómica del electorado (Wolfinger y Rosenstone, 1980). Campbell et al. (1960) argumentan que las restricciones para la incorporación al padrón (como la inscripción presencial, horarios reducidos y periodos limitados de atención) reduce el nivel de votación, especialmente entre los más pobres y menos educados. Por el contrario, liberalizar las leyes de inscripción genera un impacto positivo en las personas con menos educación (Highton, 1997; Mitchell y Wlezien, 1995).

Las barreras de entrada para la inscripción electoral son una de las múltiples dimensiones que influyen en la decisión de votar. La disminución de las barreras de entrada solo sirve para reducir costos asociados con la participación, pero no determina, por sí sola, la composición de los que se registran o acuden a votar (Mitchell y Wlezien, 1995). La composición del electorado se altera de manera marginal, siendo los más pobres y los 
con menores niveles de educación los más propensos a no participar. Al disminuir las barreras se puede producir un electorado menos interesado en la política y más volátil (Mitchell y Wlezien, 1995).

Highton (1997), en su estudio comparado sobre la relevancia de reglas fáciles de inscripción en Estados Unidos, subraya el efecto del nivel educacional en el nivel de votación en estados que poseen election-day registration or no registration. Esto se debería al mayor nivel de votación de las personas con menor nivel educacional en aquellos estados que imponen mínimos o nulos costos para registrarse. Blais, Massicotte y Dobrzynska (2003) realizaron una escala indicadora (scale indicating) para evaluar la presencia de voto ausente o anticipado, concluyendo que existía una relación positiva directa con el nivel de votación.

Hay consenso sobre la existencia de un efecto generacional (generational effect) (Franklin 2004; Rubenson et al., 2004; Toro, 2008), siendo la edad una variable significativa para explicar el declive de la participación electoral en democracias occidentales (Blais, 2008; Corvalán and Cox, 2013). Los jóvenes participan menos (Franklin, 2004; Rubenson et al., 2004), especialmente aquellos con bajos niveles de educación (Lyons y Alexander, 2000). Una razón que explica la disminución en el nivel de votación en Estados Unidos es el remplazo de la generación del New Deal (los nacidos antes de 1932) con la generación del Post-New Deal generation (los nacidos después de 1964), que participan menos, son menos propensas a identificarse con partidos, tienen una baja integración con la comunidad y poco interés en la política (Miller y Shanks, 1996). Como argumentamos más adelante, el factor generacional como variable explicativa de la caída en participación electoral es contingente con la realidad ocurrida después del retorno a la democracia en Chile.

En la vereda opuesta, Franklin (2004) plantea que más importante que el cambio en el carácter de los votantes es el cambio en el carácter de las elecciones. Una de las razones de declive de los niveles de votación es the young initiation (la iniciación juvenil). Los jóvenes enfrentan sus primeras elecciones en un muy mal momento, cuando ingresan a la universidad o comienzan a trabajar (Franklin, 2004). Un reciente estudio para el caso chileno (Corvalán y Cox, 2013), que utiliza datos agregados a nivel de comunas y encuestas de 2006 y 2009, aporta dos conclusiones novedosas. Primero, el electorado joven está fuertemente sesgado por clase social (class biased), donde el nivel de ingreso es una variable explicativa importante en la composición del registro y votación en los jóvenes. Segundo, el efecto de la edad es particularmente acentuado, considerando que las reglas de registro electoral vigentes hasta 2011 hicieron que los ya inscritos se mantuvieran permanentemente en el padrón. La intensa experiencia política de los electores que participaron en el plebiscito, en contraposición de quienes cumplieron 18 años cuando ya se había producido la transición, explicaría por qué la participación aumenta con la edad.

Mientras algunos estudios subrayan la incidencia de factores socioeconómicos como el nivel de ingreso, el nivel educacional, o la composición del electorado por cohortes etarios, otros incursionan en los efectos institucionales, tales como las barreras de entrada para ser parte de los procesos electorales o el efecto del sistema de partidos. En el caso de 
Chile, la mezcla de incentivos del diseño electoral y condiciones socioeconómicas explica la desigual caída en la participación electoral desde el retorno de la democracia hasta las elecciones de 2009, con un declive mucho mayor entre las personas de menos ingresos.

\section{ESTUDIOS SOBRE PARTICIPACIÓN ELECTORAL EN CHILE}

La participación electoral en Chile ha sido estudiada en sus dimensiones de declive electoral (Carlin, 2006; Navia, 2004; Saldaña, 2009; Toro, 2007; 2008), el aumento del abstencionismo (Cantillana, 2009; Parker, 2000; 2003) y de la votación nula y blanca (Carlin, 2006; López y Pirinoli, 2009). También ha habido interés por el nivel de participación de los jóvenes (Corvalán y Cox, 2013; Instituto Nacional de la Juventud 2004, 2008; Lehmann, 1998; Parker, 2000, 2003; Salvat, 1992; Toro, 2007; 2008). Mientras algunos plantean la hipótesis del cambio generacional (Corvalán y Cox, 2013; Toro, 2008), otros proponen comprender la participación política de manera holística. Thezá (2011), por ejemplo, entiende la participación política juvenil como un proceso altamente complejo en una sociedad inherentemente heterogénea. Así, existen múltiples posibilidades de expresarse en política (Angelcos, 2011; Thezá, 2011).

En años recientes, además, se especuló sobre los efectos que generaría una reforma al sistema de votación (Contreras et al., 2012; Fontaine et al., 2007; Fuentes y Villar, 2005; Morales, 2011; Navia, 2004). El debate público sobre los efectos de la reforma que estableció el voto voluntario se ha desarrollado en columnas de opinión, esgrimiéndose argumentos empíricos y normativos para mostrar las bondades tanto del voto obligatorio como de la votación voluntaria. El exdiputado Antonio Leal, por ejemplo, plantea que la voluntariedad del voto reconoce la autonomía individual (Leal, 2010). El académico Óscar Godoy argumenta que "el voto, en sí mismo, es un derecho político establecido por la Constitución. Pero el ejercicio de este derecho emana de la autonomía de la voluntad de las personas. Y en eso consiste la libertad" (Godoy Arcaya, 2009).

Los defensores de la votación obligatoria argumentan, como el intelectual público Carlos Peña, que la "obligación de participar -cuyo acto más obvio es el voto- no lesiona ni disminuye la libertad... Somos libres porque participamos" (Peña, 2009). Pablo Marshall y Joaquín Fernández argumentan en la misma dirección (Fernández, 2010; Marshall, 2010), al igual que el senador Ignacio Walker, la intelectual pública María Fernández, y los académicos Carlos Huneeus, Javier Couso, J. Samuel Valenzuela, Manuel A. Garretón, Tomás Chuaqui, y Claudio Fuentes (Chuaqui, 2007; Fernández, 2010; Hardy, 2005; Huneeus et al., 2008; Walker, 2010).

Los argumentos están entrelazados, por lo que generalmente la debilidad de una postura es la fortaleza de la otra. Un argumento a favor del voto voluntario es que los candidatos deben buscar el voto ciudadano, para ello acercan sus propuestas a los intereses de los votantes. El director del derechista Instituto Libertad y Desarrollo, Luis Larraín, plantea que en "sistemas de voto voluntario, los partidos políticos no solo deben lograr que las personas voten por ellos, sino que además enfrentan el desafío de que vayan a sufragar. La única forma de lograr esto es representar de mejor forma las inquietudes de los distintos 
grupos de electores" (Larraín, 2009). La senadora UDI Ena von Baer planteó que "los partidos tienen el incentivo de romper la indiferencia ciudadana entusiasmando a los votantes con sus planteamientos" (Von Baer, 2009). Pero si bien los partidos podrían ir en busca de los votantes, también pudieran querer alejar de las urnas a aquellos menos inclinados a apoyarlos. La coordinación partidista puede no buscar "romper con la indiferencia", sino que atraer y modificar la "indiferencia de sus potenciales votantes". Este argumento también es compartido por un think tank derechista (Libertad y Desarrollo, 2009).

Otro argumento a favor de la votación voluntaria es que votarán los realmente interesados, y no los que votan al azar. Pero hay evidencia que indica que la votación voluntaria disminuye la participación de los estratos sociales más pobres (Lijphart, 1997). Con datos de Power y Garand (2007) y la encuesta LAPOP, Morales (2011) construyó un modelo que determinó que la implementación de la votación obligatoria tiene un efecto positivo en la participación electoral. Morales plantea que la votación voluntaria es más corrosiva que la de la obligatoria. Mientras la desinformación es corregible, el sesgo de clase es estructural (Morales, 2011).

El senador PDC Patricio Walker sugirió entregar incentivos económicos para que la gente más joven y de menos recursos acuda a las urnas (Walker, 2010). Pero los esfuerzos de los partidos por acercar sus propuestas a los jóvenes no son incompatibles con la votación obligatoria (Morales, 2011). ¿Acaso los partidos no tendrán que hacer el mismo esfuerzo cuando los votantes jóvenes tienen que ir obligatoriamente a las urnas? Además, los partidos no solo pueden optar por ofrecer incentivos a sus potenciales votantes. Los partidos buscan maximizar su votación. Esto se puede conseguir atrayendo más votantes o ahuyentando votantes inclinados a apoyar otras opciones.

Quienes abogan por la votación obligatoria argumentan sobre los efectos nocivos de la votación voluntaria -menor participación electoral, sesgo de clase en la participación, entre otros- y el efecto preferible que tendría la votación obligatoria, que provee una mayor participación electoral (Lijphart, 1997). Otra razón esgrimida tiene que ver con las desventajas de la convivencia del voto voluntario con el sistema binominal (Morales, 2011). Si consideramos que las dos dimensiones fundamentales de la democracia son competencia y participación (Dahl, 2001), la votación voluntaria deprimiría ambas variables, significando un daño para nuestra democracia. El argumento de que los partidos deberán acercar sus propuestas a los electores -incluidos los jóvenes- no es satisfactorio para quienes defienden la votación obligatoria. Los partidos buscan obtener la votación de sus electores. Sin embargo, no hay evidencia que demuestre que en un escenario de voto obligatorio las cosas serían diferentes. La distinción está en que con la obligatoriedad del voto, los partidos deberán ir en busca de todos los electores, disminuyendo el cálculo electoral, incentivando a algunos electores y desalentando a otros.

\section{PATRONES DE PARTICIPACIÓN ELECTORAL EN CHILE}

El universo de votantes aumentó sistemáticamente desde mediados del siglo XIX, en buena medida gracias a las leyes electorales de 1874 y 1890 (Joignant, 2001; Valenzuela, 
$1985 ; 1998)$. Al eliminar requisitos de propiedad y extender el sufragio a hombres mayores de 25 años que supieran leer y escribir, se incorporó buena parte de la clase media y muchos obreros. A comienzos del siglo XX, el padrón incluía el 10\% de los mayores de 25 años (incluyendo mujeres.) En 1925, el electorado representaba el 10\% de la PEV (las mujeres y analfabetos no tenían derecho al voto). En 1935 se creó un padrón especial para mujeres y extranjeros, que se mantuvo separado del de hombres. Con el derecho a sufragio para las mujeres en elecciones presidenciales en 1949, la participación se elevó hasta alcanzar el 60\% de la PEV en 1964 y 70\% en 1973.

En las cuatro elecciones presidenciales entre 1952 y 1973 las mujeres apoyaron más a los conservadores (Neusse, 1978). Allende obtuvo mejor votación entre hombres que entre mujeres en sus cuatro campañas presidenciales. La incorporación de los analfabetos y la reducción de la edad para votar a 18 años en 1970 aumentaron el universo, pero muchos potenciales votantes no se inscribieron. Después del golpe militar de 1973 la dictadura ordenó la destrucción del padrón electoral, argumentando que el gobierno de Allende lo había manipulado para ganar las elecciones parlamentarias de 1973.

La Constitución de 1980 estableció la obligatoriedad del voto para todos los ciudadanos (Artículo 15). Siguiendo el precedente establecido en la Constitución de 1925, los extranjeros residentes por más de 5 años también tienen derecho a votar. Pero los chilenos que residen en el extranjero no pueden votar en sus países de residencia. Entre 1989 y 2010 el ejercicio del sufragio requería de una inscripción previa en el registro electoral. Pero la Ley Orgánica Constitucional $\mathrm{N}^{\mathrm{o}} 18.556$ del Sistema de Inscripciones Electorales y Servicio Electoral promulgada el 1 de octubre de 1986 no estableció la obligatoriedad de la inscripción (artículo 35, Ley N $\mathrm{N}^{\mathrm{1}}$ 18.556), creándose así la inusual combinación de inscripción voluntaria y votación obligatoria. Con la adopción de la reforma constitucional de 2009 que estableció la voluntariedad del voto (Ley N 20.337 de 4 de abril de 2009 que modificó los artículos 15 y 18 de la Constitución) y la ley que estableció la inscripción automática (Ley N 20.568 de 31 de enero de 2012), el sistema fue radicalmente modificado. Estas modificaciones entraron en vigencia para la contienda municipal de octubre de 2012.

Cuando se restablecieron los procesos electorales al fin de la dictadura, el interés por participar fue evidente. La participación en el plebiscito de 1988 fue superior al promedio histórico (Navia, 2004). Algunos han asociado esa alta participación a lo que han llamado "periodo épico" (Sierra, 2007: 160) o refundacional de la democracia (Sierra, 2007; Toro, 2008). Podemos entender el plebiscito de 1988 como lo que Miller y Shanks definen como punto de inflexión que marca y diferencia una generación política de otra (Miller y Shanks, 1996). La dictadura aspiraba a una participación lo suficientemente alta para que no se cuestionara la legitimidad del proceso, pero ya que históricamente la alta participación favoreció a la izquierda (Cruz Coke, 1984; Przeworski y Soares, 1971), una participación demasiado alta podría perjudicar a la dictadura. Hacia fines de 1987 ya había más de 3 millones inscritos, el 40\% de la PEV, en el nuevo servicio electoral (SERVEL). Cuando se cerró la inscripción 30 días antes del plebiscito había más de 7,4 millones de inscritos. El 5 de octubre de 1988, el 56\% votó contra un nuevo periodo presidencial de 8 años para el general Pinochet, forzando así el fin del régimen autoritario. 
En 1988, un tercio de los inscritos era menor de 30 años. En 2001, lo era solo el 13\%, y en 2009 llegó a 10,9\%. Aquellos entre 18 y 29 años de edad constituían el 18\% de la población en 2010, pero solo representaban el 10\% del electorado. Si bien la población adulta tiende a votar más que los jóvenes en muchas democracias (Blais, 2008; Corvalán y Cox, 2013; Franklin, 2004; Lyons y Alexander, 2000; Rubenson et al., 2004), la caída en la inscripción y participación entre los jóvenes ocurrió a un ritmo especialmente acelerado a medida que se consolidaba la democracia (Carlin, 2006; Navia, 2004; Toro, 2007; 2008). Un porcentaje bajo de personas se inscribió para votar después de 1989. Además, las trabas institucionales ayudaron a que muchos que cumplieron 18 años después de 1988 optaran por no inscribirse (Navia, 2004; Toro, 2008). Por cierto, otras variables explican las varianzas en la participación de aquellos inscritos (Navia, 2004; Navia y Joignant, 2000; Ortega Frei, 2003).

El Cuadro 1 muestra la tasa de participación electoral en el periodo 1958-1973 y durante el periodo postautoritario (1988-2012). Queda en evidencia un aumento en la participación hasta 1973 y una caída tanto en la inscripción como en la participación a partir de 1988, cuando votó el 96,6\% del padrón. Porque era la primera elección en 15 años y porque aquellos que se inscribieron lo hicieron hasta 30 días antes del plebiscito, esa tasa de participación tampoco debería ser usada como parámetro de comparación con elecciones posteriores.

La participación entre inscritos bajó a 92,3\% en 1989. La elección municipal de 1992, como es normal en contiendas locales, mostró una nueva caída, votando el 81,9\% del padrón. Las presidenciales de 1993 mostraron una mejoría (84,3\%), pero la participación volvió a caer en las municipales de 1996 (76,6\%.) En 1997, en las primeras elecciones parlamentarias no concurrentes con una elección presidencial, la participación cayó a 71,1\%. Pero subió en las presidenciales de 1999 (90\%), lo que en apariencia tuvo un efecto chorreo sobre las municipales del 2000, cuando votó el 86,8\%. Esa cifra se mantuvo casi idéntica en las parlamentarias de 2001 (86,6\%). Para las presidenciales de 2005 y 2009 la tasa de participación sobre el padrón bajó de forma leve, a 87,7\% y 83,7\%, respectivamente. Esto se puede deber al envejecimiento del padrón y a que gente que vive en lugares distintos a donde está inscrita simplemente no acudía a votar (Navia, 2004). A causa de que la ley (Ley $\mathrm{N}^{\mathrm{0}} 18.700$, art. 139) permitía excusarse a aquellos que, el día de la elección, se encontraban a más de 200 kilómetros de su lugar de inscripción y debido a que en general no se aplican multas a los abstencionistas, la tasa de participación nunca fue del 100\% (pese a la obligatoriedad del voto). De hecho, la tasa de participación cayó sistemáticamente, hasta llegar a 83,7\% de los inscritos en 2009. Luego de la instauración de la inscripción automática y el voto voluntario, la participación ha seguido decreciendo. Los resultados preliminares de la elección municipal de 2012 muestran que el nivel de participación alcanzó poco más del 40\%. La probable disminución en la participación ya había sido anticipada por algunos estudios (Morales, 2011; Contreras, González et al., 2012), a partir de la evidencia comparada sobre regímenes electorales.

El número de inscritos se mantuvo estable entre 1993 y 2010, pese a que la PEV aumentó $67 \%$, porque el número de personas que optó por no inscribirse aumentó desde 1993. Después de lograr un récord al incluir al 92\% en 1992, la PEV inscrita 
Cuadro 1: Participación electoral en Chile, 1958-2012

\begin{tabular}{lccccccc}
\hline Año & $\begin{array}{c}\text { Población } \\
\text { en edad } \\
\text { de votar }\end{array}$ & Inscritos & $\begin{array}{c}\text { Votos } \\
\text { emitidos }\end{array}$ & $\begin{array}{c}\text { Votos } \\
\text { válidos }\end{array}$ & $\begin{array}{c}\text { Nulos, blancos, } \\
\text { abstenciones y } \\
\text { no inscritos }\end{array}$ & $\begin{array}{c}\text { Votantes/ } \\
\text { Inscritos } \\
(\%)\end{array}$ & $\begin{array}{c}\text { Votos válidos/ } \\
\text { población en } \\
\text { edad de votar (\%) }\end{array}$ \\
\hline 1958 & 3.654 & 1.497 & 1.250 & 1.236 & 2.418 & 83,5 & 33,8 \\
1964 & 4.088 & 2.915 & 2.530 & 2.512 & 1.576 & 86,8 & 61,6 \\
1970 & 5.202 & 3.540 & 2.955 & 2.923 & 2.279 & 83,5 & 56,2 \\
1973 & 5.238 & 4.510 & 3.687 & 3.620 & 1.620 & 81,8 & 69,1 \\
1988 & 8.062 & 7.436 & 7.251 & 7.187 & 889 & 96,6 & 89,1 \\
1989 & 8.243 & 7.558 & 7.159 & 6.980 & 1.344 & 92,3 & 84,6 \\
1992 & 8.775 & 7.841 & 7.044 & 6.411 & 2.345 & 81,9 & 73,2 \\
1993 & 8.951 & 8.085 & 7.377 & 6.969 & 1.848 & 84,3 & 75,8 \\
1996 & 9.464 & 8.073 & 7.079 & 6.301 & 3.085 & 76,6 & 65,3 \\
1997 & 9.627 & 8.078 & 7.046 & 5.796 & 3.746 & 71,1 & 59,6 \\
1999 & 9.945 & 8.084 & 7.272 & 7.055 & 2.890 & 90,0 & 70,1 \\
2000 & 10.100 & 8.089 & 7.019 & 6.452 & 3.648 & 86,8 & 63,9 \\
2001 & 10.500 & 8.075 & 6.992 & 6.107 & 4.393 & 86,6 & 58,2 \\
2004 & 10.700 & 8.013 & 6.874 & 6.123 & 4.577 & 85,8 & 57,2 \\
2005 & 10.800 & 8.221 & 7.207 & 6.942 & 3.758 & 87,7 & 64,3 \\
2008 & 12.066 & 8.110 & 6.959 & 6.362 & 5.704 & 85,8 & 52,7 \\
2009 & 12.226 & 8.285 & 7.186 & 6.938 & 5.284 & 83,7 & 56,7 \\
2012 & 13.388 & 13.388 & 5.496 & 5.261 & 8.127 & 39,2 & 39,2 \\
\hline
\end{tabular}

Valores en miles de personas.

Fuente: Cálculos de los autores con datos de http:/ /www.ine.cl, http:/ / www.elecciones.gov.cl y Navia, 2004.

cayó continuamente. En 2010 solo el 67\% de la PEV estaba inscrita. Si sumamos nulos / blancos y abstenciones, la cifra llegó al 10,9\% en 1988. Pero el 43,3\% de la PEV no emitió votos válidos en 2009, la cantidad más alta desde 1988. Aunque una caída en la tasa de inscripción después de 1988 parecía razonable, el rápido declive con posterioridad a 1993 es preocupante. Pero como discutimos en un apartado anterior, las barreras de entrada inciden en el nivel de inscripción y en la participación (Blais, 2008; Highton, 1997; Mitchell y Wlezien, 1995). Hasta su reforma en 2011 la ley electoral obligaba a los primerizos a inscribirse al menos 90 días antes de la elección (Artículo 22, Ley $\mathrm{N}^{\mathrm{0}}$ 18.556). Pero entre 1989 y 2004 la ley establecía que el padrón se cerraba 120 días antes de una elección.

Hasta 2009, el problema de los no inscritos afectaba esencialmente a los nacidos después de 1970, aquellos que no tenían edad para votar en el plebiscito de 1988. En su encuesta de octubre de 2009, realizada a una muestra representativa del país, el Centro de Estudios Públicos reportó que el 72,7\% de los chilenos en edad de votar estaba inscrito. Esa cifra es un poco más alta de lo que se obtiene dividiendo el número de 
Cuadro 2: Inscritos y no inscritos por grupos de edad, Chile, 2009-2010

\begin{tabular}{lrrrrr}
\hline \multirow{2}{*}{$\begin{array}{l}\text { Inscrito en registro } \\
\text { electoral }\end{array}$} & \multicolumn{5}{c}{ Grupos de edad } \\
\cline { 2 - 6 } & $18-24$ & $25-34$ & \multicolumn{1}{c}{$35-44$} & 55 y más & Total \\
\hline Sí & 28,7 & 47,2 & 90,1 & 96,4 & 72,7 \\
No & 71,3 & 52,5 & 9,8 & 3,6 & 27,2 \\
Total & $100(16,7)$ & $100(20,3)$ & $100(38,8)$ & $100(24,2)$ & $100(100)$ \\
\hline & & & 2010 & \\
\hline Sí & 9,6 & 30,9 & 86,1 & 96,0 & 64,7 \\
No & 89,1 & 68,4 & 13,2 & 3,7 & 34,6 \\
Total & $100(16,7)$ & $100(20,1)$ & $100(38,7)$ & $100(24,6)$ & $100(100)$ \\
\hline
\end{tabular}

Fuente: Cálculos de los autores con datos de Encuesta CEP, octubre 2009, http:/ / www.cepchile.cl

inscritos por la estimación de población de mayores de 18 años para 2009 (67,7\%). El Cuadro 2 muestra que hasta 2011 las tasas de inscripción aumentaban junto a la edad. Mientras que solo el 28,7\% de la cohorte de edad entre 18 y 24 años estaba inscrito, el 96,4\% de los mayores de 55 años de edad lo estaba. La tasa de inscripción también era más baja en el grupo de edad entre 25 y 34 (47,2\%) que en el grupo entre 35 y 44 años de edad (90,1\%). El Cuadro 2 también muestra que en la encuesta del CEP de diciembre de 2010 el porcentaje de inscritos había bajado marcadamente respecto de un año antes (lo que posiblemente muestra algo de sesgo en las respuestas cuando no es un año electoral), con el porcentaje de inscritos alcanzando a 64,7\%. De nuevo, las tasas de inscripción son fuertemente más altas entre los grupos de edad mayores.

La Figura 1 muestra las tasas de inscripción -en porcentajes sobre el total de personas en ese grupo etáreo- para distintos cohortes de edad entre 1988 y 2010. La evidencia confirma el entusiasmo en todos los grupos en edad por participar en el plebiscito de 1988 y las elecciones de 1989 (Navia, 2004; Sierra, 2007; Toro, 2008). A partir de entonces, la tasa de inscripción en el grupo de 18 a 24 años cayó sistemáticamente hasta estabilizarse en torno al 20\%. A su vez, la tasa de inscripción en la cohorte de 25 a 34 años comenzó a caer a mediados de los 90, cuando aquellos que cumplieron 18 años después del retorno a la democracia comenzaron a entrar en esa cohorte. Finalmente, la cohorte de edad entre 35 y 44 años muestra una caída en la tasa de inscripción a partir de fines de los 90. Es evidente el quiebre entre los chilenos que tenían edad de votar para la transición a la democracia y los que cumplieron 18 años después de recuperada la democracia. En el segundo grupo, las tasas de participación son notoriamente menores.

El que la tasa de inscripción de los chilenos entre 35 y 44 años de edad inscritos haya comenzado a caer a partir de 2004 confirma nuestro argumento. Aquellos en edad de 
Figura 1: Tasas de inscripción por grupos de edad, Chile, 1988-2010

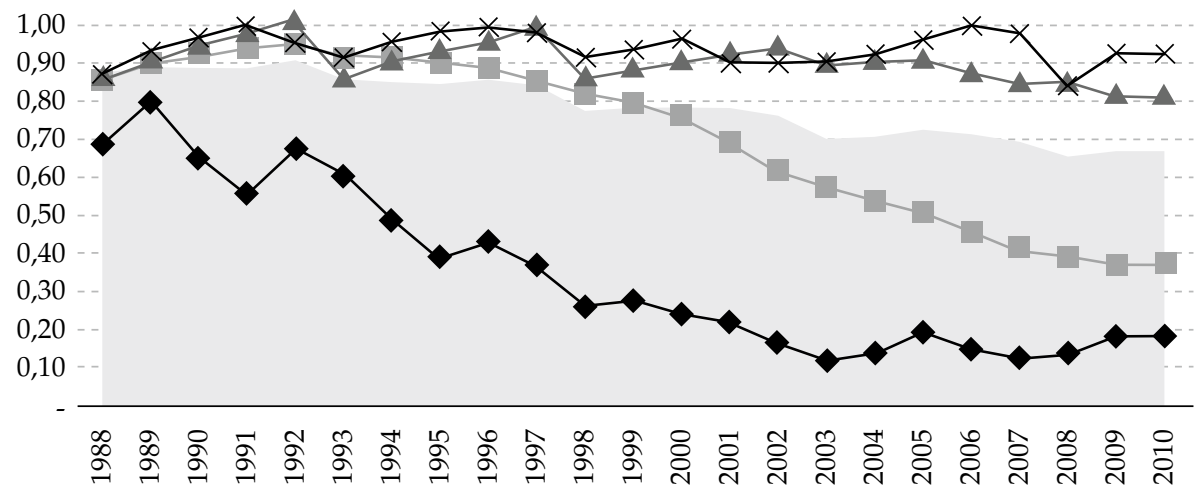

Inscritos/PEV - Inscritos en cohorte 18-24 Inscritos en cohorte 25-34

$\longrightarrow$ Inscritos en cohorte 35-44 $\multimap$ Inscritos en cohorte 45 o más

Fuente: Cálculos del autor con datos de http:/ / www.elecciones.gov.cl y http:/ /www.ine.cl

votar para la transición a la democracia se inscribieron masivamente. Pero los que cumplieron 18 años después de 1990 se inscribieron a tasas más bajas. Aunque haya una mayor tasa de inscripción entre las personas de más edad, la ola de interés electoral que llevó a la inmensa mayoría de la PEV a inscribirse durante la transición se diluyó. Hasta 2010, las tasas de inscripción eran sistemáticamente más bajas en todos los grupos de edad que cumplieron 18 años después del retorno de la democracia.

\section{LOS EFECTOS DE LA INSCRIPCIÓN AUTOMÁTICA EN EL PADRÓN}

Con las reformas que introdujeron el voto voluntario y la inscripción automática, materializadas en el nuevo padrón electoral que comenzó a regir con las municipales de octubre de 2012, el universo electoral aumentó sustancialmente. Al pasar de 8,1 millones a 13,4 millones de electores, el padrón aumentó en 65,1\%. Este aumento estuvo altamente concentrado en algunas comunas. En las dos comunas más pobladas, Maipú y Puente Alto, aumentó en 91,8\% y 127\%, respectivamente. Como muestra el Cuadro 3, en 18 de las 20 comunas más pobladas el padrón aumentó en más de 50\%. Solo en las comunas de clase media y media alta de Ñuñoa y Las Condes el aumento fue inferior a 40\%. Esto confirma que las tasas de inscripción entre personas de más ingresos eran sustancialmente más altas que en el resto del país. Como la tasa de participación es también más alta entre los grupos de más ingresos, bien pudiera ser que el aumento en el padrón electoral se traduzca en una disminución en las tasas de participación respecto del número de inscritos. De hecho, la inscripción automática constituye una disminución en las barreras de entrada, pero no asegura que los electores vayan a hacer uso de su derecho al voto. La inscripción automática es un requisito necesario, pero 
Cuadro 3: Comunas con más inscritos después de reforma de inscripción automática

\begin{tabular}{|c|c|c|c|c|c|c|}
\hline & Comuna & $\begin{array}{c}\text { Inscritos } \\
2008\end{array}$ & $\begin{array}{l}\text { Nuevos } \\
\text { inscritos }\end{array}$ & $\begin{array}{c}\text { Total de } \\
\text { inscritos } 2012\end{array}$ & $\begin{array}{l}\mathrm{N}^{\mathrm{o}} \\
\text { Conc. }\end{array}$ & $\begin{array}{c}\text { Tasa de } \\
\text { crecimiento } 2012 \\
\text { respecto de } 2009\end{array}$ \\
\hline 1 & Maipú & 174.599 & 160.344 & 334.943 & 10 & 91,8 \\
\hline 2 & Puente Alto & 144.543 & 183.638 & 328.181 & 10 & 127,0 \\
\hline 3 & Viña del Mar & 178.166 & 108.334 & 286.500 & 10 & 60,8 \\
\hline 4 & Valparaíso & 165.335 & 120.240 & 285.575 & 10 & 72,7 \\
\hline 5 & La Florida & 165.087 & 119.198 & 284.285 & 10 & 72,2 \\
\hline 6 & Santiago & 134.270 & 111.245 & 245.515 & 10 & 82,9 \\
\hline 7 & Antofagasta & 129.946 & 109.267 & 239.213 & 10 & 84,1 \\
\hline 8 & Temuco & 119.766 & 97.014 & 216.780 & 10 & 81,0 \\
\hline 9 & Las Condes & 154.578 & 60.030 & 214.608 & 10 & 38,8 \\
\hline 10 & San Bernardo & 109.074 & 98.904 & 207.978 & 10 & 90,7 \\
\hline 11 & Concepción & 127.694 & 74.042 & 201.736 & 10 & 58,0 \\
\hline 12 & Rancagua & 105.721 & 75.168 & 180.889 & 10 & 71,1 \\
\hline 13 & Peñalolén & 98.095 & 73.459 & 171.554 & 10 & 74,9 \\
\hline 14 & Ñuñoa & 121.205 & 47.737 & 168.942 & 10 & 39,4 \\
\hline 15 & Talca & 98.466 & 68.344 & 166.810 & 10 & 69,4 \\
\hline 16 & Puerto Montt & 84.236 & 74.512 & 158.748 & 8 & 88,5 \\
\hline 17 & Arica & 98.996 & 59.013 & 158.009 & 8 & 59,6 \\
\hline 18 & Pudahuel & 73.787 & 74.795 & 148.582 & 8 & 101,4 \\
\hline 19 & Providencia & 93.292 & 51.379 & 144.671 & 8 & 55,1 \\
\hline 20 & Los Ángeles & 84.565 & 59.811 & 144.376 & 8 & 70,7 \\
\hline País & 345 comunas & 8.111.514 & 5.276 .761 & 13.388 .275 & - & 65,1 \\
\hline
\end{tabular}

$\mathrm{N}^{\circ}$ Conc.: Número de concejales.

Fuente: Datos entregados por Servel http:/ /www.servel.cl

ciertamente no suficiente para inducir una mayor participación electoral (Mitchell y Wlezien, 1995).

El Cuadro 4 muestra las 20 comunas en las que más creció el padrón. Cuatro de esas veinte comunas están entre las 10 más pobladas de Chile. Las comunas con mayor crecimiento en su padrón electoral corresponden a comunas de rápido crecimiento en la capital (Puente Alto, La Pintana, Pudahuel, Quilicura, Renca, San Bernardo), a centros urbanos de la zona minera del norte (Antofagasta, Alto Hospicio) y de la zona de la acuicultura del sur (Puerto Montt, Quinchao, Castro). Las zonas tradicionalmente agrícolas del centro del país no están entre aquellas que más vieron crecer su número de votantes. 
Cuadro 4: Veinte comunas con mayores tasas de crecimiento en número de inscritos, 2012

\begin{tabular}{rlrcrrc}
\hline Reg. & Comuna & $\begin{array}{c}\text { Inscritos } \\
\text { 2008 }\end{array}$ & $\begin{array}{c}\text { Nuevos } \\
\text { inscritos }\end{array}$ & $\begin{array}{c}\text { Inscritos } \\
2012\end{array}$ & $\begin{array}{c}\mathrm{N}^{\text {o }} \\
\text { Conc. }\end{array}$ & $\begin{array}{c}\text { Tasa de } \\
\text { crecimiento 2012 } \\
\text { respecto de 2009 }\end{array}$ \\
\hline 1 & Huara & 3.450 & 5.527 & 8.977 & 6 & 160,2 \\
13 & Puente Alto & 144.543 & 183.638 & 328.181 & 10 & 127,0 \\
13 & Alhué & 2.906 & 3.651 & 6.557 & 6 & 125,6 \\
13 & La Pintana & 57.904 & 71.926 & 129.830 & 8 & 124,2 \\
1 & Alto Hospicio & 19.327 & 20.690 & 40.017 & 6 & 107,1 \\
13 & Pudahuel & 73.787 & 74.795 & 148.582 & 8 & 101,4 \\
13 & Quilicura & 55.683 & 53.381 & 109.064 & 8 & 95,9 \\
13 & Maipú & 174.599 & 160.344 & 334.943 & 10 & 91,8 \\
10 & Quellón & 10.527 & 9.553 & 20.080 & 6 & 90,7 \\
13 & San Bernardo & 109.074 & 98.904 & 207.978 & 10 & 90,7 \\
13 & Lampa & 20.896 & 18.675 & 39.571 & 6 & 89,4 \\
9 & Pucón & 11.577 & 10.326 & 21.903 & 6 & 89,2 \\
10 & Puerto Montt & 84.236 & 74.512 & 158.748 & 8 & 88,5 \\
10 & Futaleufú & 1.737 & 1.528 & 3.265 & 6 & 88,0 \\
10 & Quinchao & 4.841 & 4.239 & 9.080 & 6 & 87,6 \\
10 & Castro & 19.553 & 16.738 & 36.291 & 6 & 85,6 \\
13 & Renca & 59.882 & 50.820 & 110.702 & 8 & 84,9 \\
2 & Antofagasta & 129.946 & 109.267 & 239.213 & 10 & 84,1 \\
10 & Calbuco & 15.877 & 13.328 & 29.205 & 6 & 83,9 \\
13 & Colina & 35.646 & 29.846 & 65.492 & 6 & 83,7 \\
Total & 345 comunas & 8.111 .514 & 5.276 .761 & & - & 65,1 \\
\hline & & & & & & \\
\hline
\end{tabular}

\section{DETERMINANTES SOCIOECONÓMICOS DE INSCRIPCIÓN Y PARTICIPACIÓN ELECTORAL}

Hasta 2009, la condición de inscripción electoral en Chile estaba determinada fundamentalmente por dos factores. Primero, la mayoría de edad al momento del plebiscito en 1988. Aquellos que tenían más de 18 años para la transición a la democracia estaban inscritos casi en su totalidad. Segundo, para aquellos que cumplieron 18 años con posterioridad a 1989, la condición de inscripción era función de variables sociodemográficas que usualmente se asocian con determinantes de participación, como los niveles de educación, condición socioeconómica e interés personal en la política (Blais, 2008; Franklin, 2004; Green and Gerber, 2008; Hajnal, 2010).

La Figura 2 muestra que para los que tenían edad de votar en 1988-1989, la tasa de inscripción era cercana al 100\%. Ya sea porque se inscribieron entonces -o bien porque 
Figura 2: Tasas de inscripción por escolaridad para nacidos hasta 1971 y después (mayores de edad en 1989)

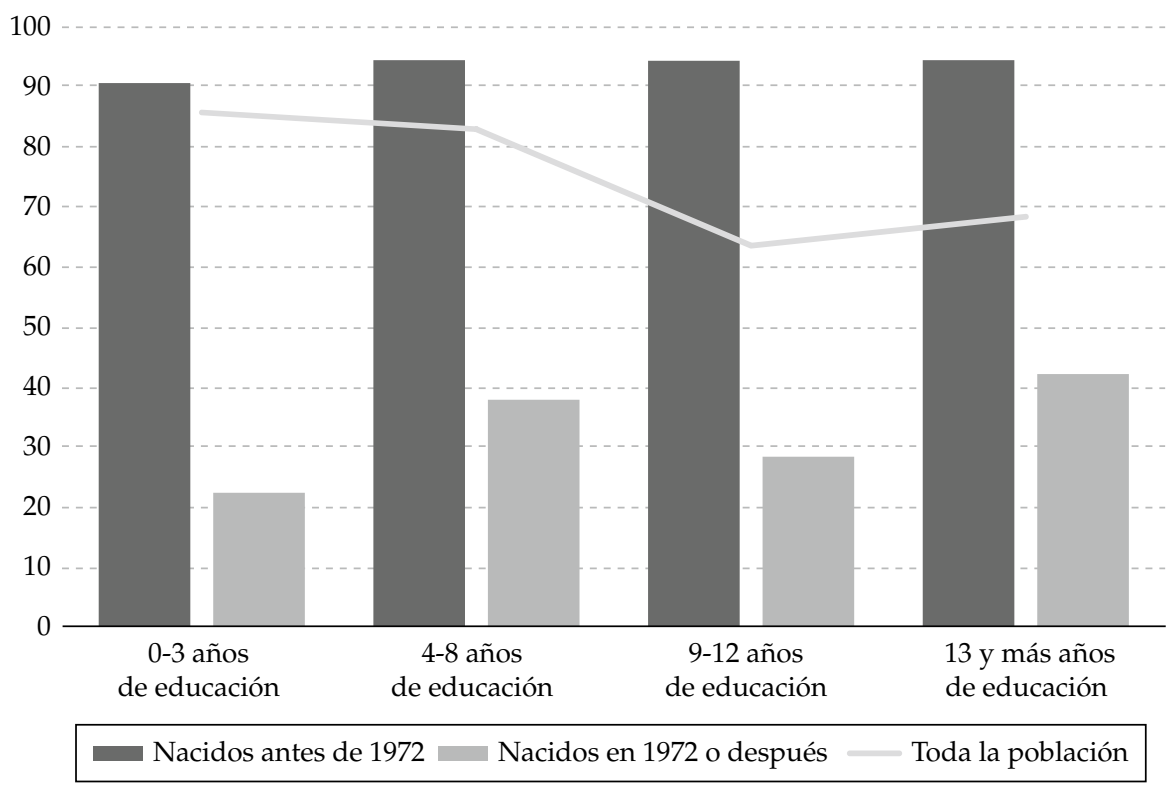

Fuente: Elaboración propia con datos de la Encuesta CEP \#63, diciembre de 2010.

lo hicieron después-, los que eran ya adultos cuando se produjo la transición estaban inscritos casi en su totalidad. En cambio los que fueron alcanzando la adultez con posterioridad mostraban tasas de inscripción marcadamente más bajas (Corvalán and Cox, 2013; Parker, 2000; 2003; Toro, 2007; 2008). Por eso, cuando se analiza la población en general, las tasas de inscripción electoral están negativamente correlacionadas con la educación. Contrario a lo que señala la literatura comparada que a mayor educación habrá mayores niveles de participación (Blais, 2008; Franklin, 2004; Hajnal, 2010), en Chile aquellos con menos educación muestran tasas de inscripción superiores. Pero eso es una anomalía que resulta de la forma en que entró la gente al padrón en Chile. La mayor tasa de inscripción en personas con menos educación en Chile era función del hecho que la gran mayoría de los chilenos con pocos años de educación pertenecen a los grupos de más edad. De hecho, más del 90\% con menos de 8 años de educación están en el grupo nacido en 1971 o antes (que por lo tanto ya tenía edad de votar en 1989).

Al separar a la población en dos grupos -aquellos que tenían edad de votar en 1988-89 y aquellos que cumplieron 18 años después de la transición a la democracia- vemos que la educación no es una variable relevante para los mayores, pero sí parece serlo para aquellos que cumplieron 18 años después de 1988-89. Entre aquellos que cumplieron mayoría de edad después del retorno de la democracia, la tasa de inscripción se comportaba de la forma que señala la literatura comparada, a mayor nivel de educación, mayor es la probabilidad de estar inscrito (Blais, 2008; Franklin, 2004; Hajnal, 2010). De ahí que tenga 
sentido realizar el análisis dividiendo a la población entre aquellos que tenían edad de votar para el plebiscito (donde la inscripción se acercó al 100\% y donde los niveles de educación eran más bajos) y aquellos que cumplieron 18 años después (donde las tasas de inscripción varían de acuerdo con los niveles de educación).

Por eso, es razonable realizar un análisis sobre los factores que determinaban la condición de inscripción solo entre aquellos que cumplieron 18 años después de la transición a la democracia. Si incorporamos a aquellos que ya tenían 18 años para el plebiscito los resultados se contaminan, porque en ese grupo la condición de inscripción es universal. Además, los niveles educacionales entre los chilenos de más edad tienen un rango sustancialmente mayor que entre los más jóvenes, donde el porcentaje que tiene menos de 12 años de educación es ínfimo.

Para evaluar los determinantes de la condición de inscripción en las personas que cumplieron 18 años después de la transición, realizamos una ecuación logística ordinal, usando datos de la encuesta del CEP de diciembre de 2010. En el modelo, las variables explicativas son las que comúnmente se utilizan para explicar el interés en la política, como la edad, el nivel socioeconómico (que incorpora ingresos y niveles de educación, dos variables altamente correlacionadas) e identificación ideológica (Aldrich, 1993; Blais, 2008; Blais, Massicotte, y Dobrzynska, 2003; Fauvelle-Aymar, Lafay, y Servais, 2000; Franklin, 2004; Hajnal, 2010; Highton, 1997; Jackman y Miller, 1995; Uhlaner, 1989). Nótese que ya que usamos la escala ideológica incorporando tanto simpatías con la izquierda, el centro y la derecha así como con la opción "ninguno", resulta apropiado el uso de un modelo ordinal logit, donde las variables independientes puedan ser categóricas (izquierda, centro, derecha, ninguno) y la variable dependiente sea dicotómica (inscrito o no inscrito en el padrón).

El Cuadro 5 muestra tres modelos que subrayan este mismo punto. El Modelo 1 incluye a toda la muestra en la encuesta CEP de diciembre de 2010. El Modelo 2 incluye solo a aquellos nacidos después de 1971. El Modelo 3 solo incluye a aquellos nacidos en 1971 o antes. La decisión de establecer 1971 como punto de quiebre radica en que todos los nacidos en ese año o antes tuvieron la posibilidad de votar en las elecciones de 1989, las fundacionales de la democracia actual.

Los modelos del Cuadro 5 muestran que los determinantes de la condición de inscripción varían sustancialmente entre ambos grupos etáreos. Cuando tomamos toda la población, la posición ideológica comprensiblemente es significativa para explicar la condición de inscripción en los registros electorales. La edad también es significativa. Mientras menor la edad, menos probable es que estén inscritos para votar. Pero los efectos de la condición socioeconómica no son significativos, salvo para el grupo C2. El efecto de la condición socioeconómica solo es perceptible cuando dividimos la muestra por grupos de edad.

Ahora bien, entre los nacidos en 1971 o antes, el 94\% de la muestra en la encuesta CEP estaba inscrito para votar. Pero entre los nacidos después de 1971 solo el 34\% estaba inscrito. Ya que la condición de inscripción es casi universal para la gente de más edad, no sorprende que en el Modelo 3 ninguna de las variables explicativas sea significativa. Pero en el Modelo 2, donde el porcentaje de inscritos es sustancialmente menor, las 
variables de identificación ideológica y condición socioeconómica son significativas en la dirección esperada. Entre los nacidos después de 1971 la gente con posiciones ideológicas más marcadas tiene más posibilidades de estar inscrito que aquellos que no se identifican en el eje izquierda-derecha. De la misma forma, la probabilidad de estar inscrito aumenta entre las personas de mejor condición socioeconómica.

Para los nacidos antes de 1971 la edad tampoco es significativa. Esto porque en 1988 se inscribió casi el 100\% de la PEV. Pero para los nacidos después de 1971 la edad sí es una variable significativa. Mientras mayor la edad, más probable es que estén inscritos. Esto es consistente con nuestro argumento central. La cercanía a una mayoría de edad cuando se produjo la transición a la democracia aumenta la probabilidad de estar inscrito en los registros electorales.

Al separar a la población entre los que tenían edad de votar para la transición y los que cumplieron 18 años después, podemos identificar las variables que explican la condición de inscripción entre los más jóvenes. Entre los que cumplieron 18 años en democracia las probabilidades de estar inscrito en 2010 aumentaban significativamente entre aquellos con posiciones claras en el eje ideológico izquierda-centro-derecha, entre aquellos de nivel socioeconómico más alto y entre las personas de más edad. Así, los jóvenes de menos ingresos sin una firme identificación política son los que menos probabilidades tenían de estar inscritos. De no haberse adoptado la inscripción automática, el padrón electoral de forma creciente avanzaría hacia una composición fundamentalmente de personas de más edad, con marcada identificación política y niveles socioeconómicos más altos.

El Modelo 2 captura a aquellos incorporados al padrón con la reforma que estableció la voluntariedad del voto y la automatización de la inscripción electoral. A partir del Modelo 2, podemos anticipar que la probabilidad de participar en las contiendas electorales aumentará entre aquellos que se identifican políticamente con algún sector, de izquierda, centro o derecha. De la misma forma, habrá mayor participación entre aquellos de nivel socioeconómico más alto.

Al separar a la población entre aquellos nacidos en 1971 o antes y los que nacieron después -y por lo tanto no tenían edad para votar durante la transición- encontramos que las explicaciones presentes en la teoría sobre el porqué votan las personas aplican bien en Chile a los nacidos después de 1971. Aquellos que ya tenían 18 años para la transición estaban en su gran mayoría inscritos y por lo tanto estaban sujetos a la votación obligatoria. Pero entre aquellos nacidos después de 1971, la tasa de participación era, para todos los efectos prácticos, voluntaria. En ese grupo, las predicciones de la teoría que relacionan la disposición a votar a más edad, mayores ingresos (y educación) e identificación en la escala ideológica funcionan bien para explicar el comportamiento electoral de los chilenos.

La evidencia del Cuadro 5 subraya tanto los argumentos sobre incentivos institucionales que influyen en la tasa de participación como los resultados reportados en estudios de otros países sobre el efecto de la edad y la educación en la participación electoral. Adicionalmente, los datos del Cuadro 3 también muestran la presencia de un efecto generacional (Blais, 2006; Franklin, 2004; Rubenson et al., 2004) en la participación electoral 
Cuadro 5: Modelos Ordinal Logit para predecir condición de inscripción electoral

\begin{tabular}{|c|c|c|c|}
\hline & $\begin{array}{c}\text { Modelo } 1 \\
\text { Toda la muestra }\end{array}$ & $\begin{array}{l}\text { Modelo } 2 \\
\text { Nacidos después de } 1971\end{array}$ & $\begin{array}{c}\text { Modelo } 3 \\
\text { Nacidos en } 1971 \text { o antes }\end{array}$ \\
\hline Sexo & $\begin{array}{l}-0,111 \\
(0,171)\end{array}$ & $\begin{array}{c}0,063 \\
(0,224)\end{array}$ & $\begin{array}{l}-0,448 \\
(0,298)\end{array}$ \\
\hline \multicolumn{4}{|c|}{ Posición política } \\
\hline Derecha & $\begin{array}{l}0,896 \\
(0,269)^{* *}\end{array}$ & $\begin{array}{l}1,307 \\
(0,338)^{* *}\end{array}$ & $\begin{array}{c}0,313 \\
(0,446)\end{array}$ \\
\hline Centro & $\begin{array}{c}0,619 \\
(0,246)^{*}\end{array}$ & $\begin{array}{c}0,861 \\
(0,304)^{* *}\end{array}$ & $\begin{array}{c}0,337 \\
(0,472)\end{array}$ \\
\hline Izquierda & $\begin{array}{l}0,633 \\
(0,227)^{* *}\end{array}$ & $\begin{array}{l}1,032 \\
(0,274)^{* *}\end{array}$ & $\begin{array}{l}-0,045 \\
(0,402)\end{array}$ \\
\hline Ninguno & , & , & , \\
\hline \multicolumn{4}{|c|}{ GSE } \\
\hline $\mathrm{ABC1}$ & $\begin{array}{l}1,240 \\
(0,649)\end{array}$ & $\begin{array}{l}1,485 \\
(0,748)^{*}\end{array}$ & $\begin{array}{c}0,309 \\
(1,061)\end{array}$ \\
\hline $\mathrm{C} 2$ & $\begin{array}{c}0,733 \\
(0,339)^{*}\end{array}$ & $\begin{array}{l}0,844 \\
(0,413)^{*}\end{array}$ & $\begin{array}{c}0,582 \\
(0,631)\end{array}$ \\
\hline C3 & $\begin{array}{c}0,194 \\
(0,178)\end{array}$ & $\begin{array}{c}0,133 \\
(0,228)\end{array}$ & $\begin{array}{c}0,486 \\
(0,337)\end{array}$ \\
\hline $\mathrm{D} / \mathrm{E}$ & , & , & , \\
\hline \multicolumn{4}{|c|}{ Percepción económica } \\
\hline Mala y muy mala & $\begin{array}{c}0,144 \\
(0,357)\end{array}$ & $\begin{array}{c}0,240 \\
(0,341)\end{array}$ & $\begin{array}{l}-0,088 \\
(0,459)\end{array}$ \\
\hline Ni buena ni mala & $\begin{array}{c}0,128 \\
(0,220)\end{array}$ & $\begin{array}{c}0,270 \\
(0,279)\end{array}$ & $\begin{array}{c}0,029 \\
(0,418)\end{array}$ \\
\hline Buena y muy buena & , & , & , \\
\hline \multicolumn{4}{|c|}{ Edad } \\
\hline 18-24 años & $\begin{array}{l}-5,153 \\
(0,345)^{* *}\end{array}$ & $\begin{array}{l}-2,546 \\
(0,332)^{* *}\end{array}$ & - \\
\hline 25-34 años & $\begin{array}{l}-3,613 \\
(0,275)^{* *}\end{array}$ & $\begin{array}{l}-0,943 \\
(0,259)^{* *}\end{array}$ & - \\
\hline 35-54 años & $\begin{array}{l}-1,169 \\
(0,265)^{* *}\end{array}$ & - & $\begin{array}{l}-0,411 \\
(0,302)\end{array}$ \\
\hline $\begin{array}{l}55 \text { y más } \\
\text { (35 a } 54 \text { en el modelo 2) }\end{array}$ & , & ${ }^{\prime}$ & , \\
\hline Constante & $\begin{array}{l}2,528 \\
(, 330)^{* *}\end{array}$ & $\begin{array}{l}-0,489 \\
(0,376)\end{array}$ & $\begin{array}{l}2,928 \\
(0,505)^{* *}\end{array}$ \\
\hline Chi Square & 612,750 & 103,422 & 8,566 \\
\hline$-2 \log$ verosimilitud & 421,118 & 279,008 & 167,671 \\
\hline $\mathrm{R}^{2}$ de Cox y Snell & 0,367 & 0,191 & 0,010 \\
\hline $\mathrm{R}^{2}$ de Nagelkerke & 0,529 & 0,264 & 0,028 \\
\hline $\mathrm{R}^{2} \mathrm{McFadden}$ & 0,387 & 0,165 & 0,023 \\
\hline $\mathrm{N}$ & 1342 & 489 & 853 \\
\hline
\end{tabular}

** Significativo al 0,01. * Significativo al 0,05. 
en Chile. Aquellos que tenían 18 años para la transición están inscritos en su totalidad y votaban en altos porcentajes cuando la votación era obligatoria. En ese grupo no hay varianza en la variable dependiente. De ahí que resulte apropiado dividir la población entre aquellos que tenían edad para votar durante la transición y los que cumplieron 18 años después del retorno de la democracia. En ese segundo grupo la ideología importa. Mientras más decididamente ideologizados, más probable es que voten. A su vez, el nivel socioeconómico es relevante entre el grupo de los nacidos después de 1971 (no entre los que tenían edad para votar en 1988). Entre los más jóvenes, la probabilidad de participar (que hasta 2009 implicaba el acto de inscribirse en el padrón electoral para luego tener que participar obligatoriamente) disminuía a medida que disminuía el nivel socioeconómico.

A diferencia de estudios que utilizan datos agregados a nivel comunal o datos de encuestas sin distinguir entre las dos generaciones marcadamente distintas de chilenos (Corvalán y Cox, 2013), al separar la población entre aquellos que tenían edad de votar para la transición y el resto, encontramos marcadas diferencias en la probabilidad de estar inscrito en el padrón en 2009. Entre los nacidos después de 1971, aquellos con más educación y mayor nivel socioeconómico tenían más probabilidades de estar inscritos en el padrón -y por lo tanto votar- que sus compañeros de generación con menos educación y de menor nivel socioeconómico.

Utilizamos un modelo ordinal logit, ya que la identificación política (izquierda, centro, derecha, ninguna) es ordinal y no incremental. En el contexto de la discusión sobre los efectos de la inscripción automática y el voto voluntario, los resultados del Cuadro 3 sugieren ser cautos sobre las expectativas de una mayor participación, debido a que ahora están automáticamente inscritos todos los chilenos. Porque la probabilidad de participar dependía de la condición de inscripción, pero la condición de inscripción era un acto voluntario, podemos especular que el nuevo sistema de inscripción automática y voto voluntario no tendrá demasiados efectos en la participación electoral entre los nacidos después de 1971. Para aquellos que ya tenían edad de votar para la transición, la condición de voluntariedad del voto pudiera hacer bajar la participación. Pero para aquellos que no tenían edad de votar para la transición a la democracia, la automaticidad de la inscripción debiera contribuir solo marginalmente a aumentar la participación. Al eliminar una barrera de entrada se hace más fácil que todos puedan votar. Pero en tanto la disponibilidad a participar (la voluntad de estar inscrito) entre los nacidos después de 1971 aumentaba entre aquellos con más educación y de nivel socioeconómico más alto, la automaticidad de la inscripción bien pudiera tener efectos solo marginales en la participación.

\section{CONCLUSIONES}

Después de revisar la discusión teórica que explica los determinantes de la participación electoral, analizamos su evolución en Chile antes de 1973 y después de 1989. Mostramos que la caída en las tasas de inscripción y en la participación electoral después del retorno 
de la democracia está asociada con niveles de ingresos y posición ideológica. Después que casi todos los chilenos en edad de hacerlo se inscribieran para votar en 1988-1989, los inscritos que cumplieron 18 años después del retorno de la democracia reflejaban la sobrerrepresentación de los grupos de más edad, de nivel socioeconómico más alto y de posiciones ideológicas más definidas en el eje izquierda-derecha.

A diferencias de trabajos anteriores que han asociado las diferencias en tasas de inscripción y participación electoral a la edad, nosotros destacamos un elemento generacional que da cuenta de esa diferencia. Aquellos que llegaron a la mayoría de edad después de la transición a la democracia muestran menores tasas de inscripción y participación a medida que envejecen. Este no es un comportamiento asociado a la edad de las personas, sino a su tasa de inscripción. De ahí que las tasas de participación más bajas entre la gente de menos edad deba asociarse más a una variable generacional, de la que habla la literatura para el caso de Estados Unidos por ejemplo, que simplemente a una función de la edad de los potenciales votantes.

De igual forma, las tasas de participación más altas entre personas de menos nivel educacional en Chile están asociadas al hecho de que esas personas están altamente concentradas en los grupos de más edad, que son los que más votan. De ahí que otros estudios no encuentren evidencia que asocie la mayor participación a niveles más altos de educación. Pero cuando controlamos por edad, la participación efectivamente está asociada a mayores niveles de educación. La amplia discusión en la literatura que asocia la participación a mayores niveles de educación aplica también en el caso de Chile, pero solo cuando controlamos por el hecho de que aquellos que ya eran mayores de edad para la transición votan casi en su totalidad. En la población más joven, la participación está asociada a los niveles de educación. Aquí complementamos con datos de encuestas los resultados reportados por otros investigadores que llegan a conclusiones similares usando datos de votación a nivel de comunas.

Hasta la reforma que estableció la voluntariedad del voto y la automatización de la inscripción electoral, el universo de votantes habilitados en Chile crecientemente avanzó hacia la sobrerrepresentación de personas de más edad, mayores niveles de educación y nivel socioeconómico más alto. Con la adopción de la inscripción automática se han corregido esos sesgos en el universo de potenciales votantes. Pero la adopción de la votación voluntaria bien pudiera tener efectos de generar un nuevo sesgo a favor de una mayor participación entre aquellas personas de mayor nivel educacional y nivel socioeconómico más alto. De hecho, entre aquellos que cumplieron 18 años después de la transición -y para quienes la inscripción electoral, y la votación, era voluntariaaplican muy bien los determinantes de participación identificados en la literatura. En este grupo, aquellos de más ingresos, más identificados ideológicamente y los de más edad tienen más posibilidades de votar que el resto. De aquí que resultaría necesario adoptar medidas que disminuyan los potenciales efectos nocivos de la participación voluntaria. Se deben diseñar políticas públicas que impidan que los más pobres dejen de votar, que incentiven a los jóvenes a participar, y que eviten que los recursos de partidos y candidatos se destinen a atraer votantes afines y ahuyentar a otros votantes. 


\section{REFERENCIAS}

Aldrich, John H. 1993. "Rational Choice and Turnout". American Journal of Political Science 37 (1): 246-278. Almond, Gabriel A. and Sidney Verba. 1963. The Civic Culture. Princeton: Princeton University Press.

Angelcos, Nicolás. 2011. Elementos para una crítica de la despolitización en Chile. Revista Observatorio de Juventud 29 (Julio): 64-84.

Blais, André. 2006. "What affects voter turnout?". Annual Review of Political Science 9: 111-125.

Blais, André. 2008. “QQué afecta a la participación electoral?”. Revista Española de Ciencia Política 18: 9-27.

Blais, André. 2008. "Turnout in Elections". En Oxford Handbook of Political Behavior, eds. Russel J Dalton y Hans-Dieter Klingemann. New York: Oxford University Press.

Blais, André, Louis Massicotte, y Agnieszka Dobrzynska. 2003. Why is Turnout Higher in Some Countries than in Others? Ottawa: Elections Canada.

Blais, André, y Ken Carthy. 1990. “Does proportional representation foster voter turnout?". European Journal of Political Research 18: 167-181.

Campbell, Angus, Pihilip E. Converse, Warren E. Miller, y Donald E. Stokes. 1960. The American Voter. New York: Wiley.

Cantillana, Carlos. 2009. "Inscritos que no votan: la abstención electoral en Chile y sus factores explicativos". En El genoma electoral chileno. Dibujando el mapa genético de las preferencias políticas en Chile, eds. Patricio Navia, Renato Briceño Espinoza y Mauricio Morales, 77-96. Santiago: Ediciones Universidad Diego Portales.

Carlin, R. 2006. "The decline of citizen participation in electoral politics in post-authoritarian Chile". Democratization 13 (4): 632-651.

Chuaqui, Tomás. 2007. "Participación electoral obligatoria: una defensa". En Modernización del régimen electoral chileno, eds. Arturo Fontaine, Cristián Larroulet, José Antonio Viera-Gallo y Ignacio Walker, 183-203. Santiago: CEP/Libertad y Desarrollo/PNUD/CIEPLAN.

Contreras, Gonzalo, Florencia González, Mauricio Morales, y Daniela Oliva. 2012. “Nuevo régimen electoral en Chile. Inscripción automática y voto voluntario". En Democracia Municipal en Chile, 1992-2010, eds. Mauricio Morales and Patricio Navia, 65-94. Santiago: Ediciones Universidad Diego Portales.

Corvalán, Alejandro, y Paulo Cox. 2013. When Generational Replacement is Class Biased: Chilean Turnout (1989-2008). Latin American Politics and Society (forthcoming).

Cruz Coke, Ricardo. 1984. Historia electoral de Chile. 1925-1973. Santiago: Editorial Jurídica de Chile.

Dahl, Robert A. 2001. "La poliarquía". En Diez textos básicos de ciencia política, ed. Albert Batlle, 77-92. Barcelona: Ariel.

Downs, Anthony. 1957. An Economic Theory of Democracy. New York: Harper \& Row.

Downs, Anthony. 2001. "Teoría económica de la acción política en una democracia". En Diez textos básicos de ciencia política, ed. Albert Batlle, 93-112. Barcelona: Ariel.

Fauvelle-Aymar, Christine, Jean-Dominique Lafay, y Marie Servais. 2000. "The Impact of Turnout on Electoral Choices: An Econometric Analysis of the French Case". Electoral Studies 19: 392-412.

Ferejohn, John, and Morris Fiorina. 1974. "The Paradox of Not Voting: A Decision Theoretic Analysis". American Political Science Review 68 (2): 525-536.

Fernández, Joaquín. 2010. “Sobre la obligatoriedad del voto: ¿conveniente para quiénes?". El Mostrador, 18 de noviembre.

Fontaine, Arturo, Cristián Larroulet, José Antonio Viera-Gallo, e Ignacio Walker, eds. 2007. Modernización del régimen electoral chileno. Santiago: CIEPLAN/Libertad y Desarrollo/CEP.

Fornos, Carolina A, Timothy J Power, y James C Garand. 2004. “Explaining Voter Turnout in Latin America, 1980 to 2000". Comparative Political Studies 37 (8): 909-940.

Franklin, Mark N. 1996. "Electoral Participation". En Comparing Democracies: Elections and Voting in Global Perspective, eds. Lawrence LeDuc, Richard Niemi y Pippa Norris. Thousand Oaks, CA: Sage. 220-242.

Franklin, Mark N. 2004. Voter Turnout and the Dynamics of Electoral Competition in Established Democracies Since 1945. New York: Cambridge University Press.

Fuentes, Claudio, y Andrés Villar, eds. 2005. Voto ciudadano. Debate sobre la inscripción electoral. Santiago: FLACSO. 
Godoy Arcaya, Oscar. 2009. "Sobre el voto voluntario". El Mercurio, 6 de enero.

Green, Donald P. y Alan S. Gerber. 2008. Get Out the Vote. How to Increase Voter Turnout. Second Edition. Washington: Brookings.

Hajnal, Zoltan. 2010. America's Uneven Democracy. Race, Turnout and Representation in City Politics. New York: Cambridge University Press.

Hardy, Clarisa. 2005. "Inscripción automática y voto obligatorio". En Voto ciudadano: Debate sobre la inscripción electoral, eds. Claudio Fuentes y Andrés Villar, 115-117. Santiago: FLACSO.

Highton, Benjamin. 1997. "Easy Registration and Voter Turnout". Journal of Politics 59 (May): 565-576.

Huneeus, Carlos, María de los Ángeles Fernández, Javier Couso, y Samuel Valenzuela. 2008. "El voto voluntario es un retroceso histórico". El Mercurio, 31 de diciembre.

Instituto Nacional de la Juventud. 2004. "Participación política juvenil: dilemas y tensiones actuales". Revista Observatorio de Juventud 4 (Diciembre), 6-42.

Instituto Nacional de la Juventud. 2008. "Sistema electoral y participación juvenil". Revista Observatorio de Juventud 19 (Septiembre), 5-71.

Jackman, Robert W. 1987. "Political Institutions and Voter Turnout in the Industrial Democracies". American Political Science Review 81: 405-423.

Jackman, Robert W. y Ross A. Miller. 1995. "Voter Turnout in the Industrial in the Industrial Democracies During the 1980s". Comparative Political Studies 27 (4): 467-492.

Joignant, Alfredo. 2001. "El lugar del voto. La ley electoral de 1874 y la invención del ciudadano-elector en Chile". Estudios Públicos 81: 245-275.

Larraín, Luis. 2009. “QQuién le teme al voto de los jóvenes?”. El Mercurio.19 de abril.

Leal, Antonio. 2010. "Voto voluntario: Atreverse a la incertidumbre". El Mostrador, 4 de noviembre.

Lehmann, Carla. 1998. "La voz de los que no votaron". Puntos de Referencia, Centro de Estudios Públicos 197.

Libertad y Desarrollo. 2009. "Voto voluntario: mayor calidad de la democracia". Temas Públicos 907 (6 de marzo).

Lijphart, Arend. 1997. “Unequal Participation: Democracy's Unresolved Dilemma. Presidential Address. American Political Science Association 1996". American Political Science Review 91 (1): 1-14.

López, Montserrat, and Sergio Pirinoli. 2009. "¿Quiénes votaron nulo y blanco en Chile en 1999 y 2005?". En El genoma electoral chileno, eds. Patricio Navia, Mauricio Morales y Renato Briceño, 97-116. Santiago: Ediciones Universidad Diego Portales.

Lyons, Williams, y Robert Alexander. 2000. "A Tale of Two Electorates: Generational Replacement and the Decline of Voting in Presidential Elections". Journal of Politics 62: 1014-1034.

Marshall, Pablo. 2010. “¿Cómo afecta el voto obligatorio a la libertad?”. El Mostrador, 2 de diciembre.

Miller, Warren E. y J. Merrill Shanks. 1996. The New American Voter. Cambridge, MA: Harvard University Press.

Mitchell, Glenn E. y Christiopher Wlezien. 1995. “The Impact of Legal Constraints on Voter Registration, Turnout, and the Composition of the American Electorate". Political Behavior 17 (2): 179-202.

Morales, Mauricio. 2011. "Precauciones frente al voto voluntario". En Chile 2010. Sexta Encuesta Nacional UDP: Percepciones y actitudes sociales, 59-72. Santiago.

Navia, Patricio. 2004. “Participación electoral en Chile 1988-2001". Revista de Ciencia Politica 24 (1): 81-103.

Navia, Patricio, y Alfredo Joignant. 2000. “Las elecciones presidenciales de 1999: la participación electoral y el nuevo votante chileno". En Chile 1999-2000. Nuevo Gobierno: Desafios de la reconciliación, ed. Francisco Rojas, 119-144. Santiago: FLACSO.

Neusse, Steven. 1978. "Voting in Chile. The Femenine Response". En Political Parties in Latin America, eds. John Booth y Mitchell Seligson, 129-144. New York: Holmes and Meier Publishers, Inc.

Norris, Pippa. 2004. Electoral Engineering. Voting Rules and Political Behavior. New York: Cambridge University Press.

Ortega Frei, Eugenio. 2003. “Los partidos políticos chilenos: Cambio y estabilidad en el comportamiento electoral 1990-2000". Revista de ciencia política 23 (2): 109-147.

Parker, Cristián. 2000. Los Jóvenes chilenos: cambios culturales; perspectivas para el siglo XXI. of Unidad de Estudios Prospectivos. Santiago: Mideplan.

Parker, Cristián. 2003. "Abstencionismo, juventud y política en Chile actual". Revista de Estudios Avanzados Inter@ctivos 2 (4): 1-23. 
Peña, Carlos. 2009. "El deber de votar". El Mercurio, 25 de enero.

Pérez-Liñán, Aníbal. 2001. "Neoinstitutional Accounts of Voter Turnout: Moving Beyond Industrial Democracies". Electoral Studies 20: 281-297.

Powell Jr., G. Bingham. 1986. American Voter Turnout in Comparative Perspective. American Political Science Review 80 (1): 17-43.

Przeworski, Adam, y Glaucio G. Soares. 1971. “Theories in Search of a Curve - Contextual Interpretation of Left Vote". American Political Science Review 65 (1): 51-68.

Rubenson, Daniel, André Blais, Patrick Fournier, Elisabeth Gidengil y Neil Nevitte. 2004. "Accounting for the Age Gap in Turnout". Acta Politica 39: 407-421.

Saldaña, Jorge. 2009. "Crisis en la participación electoral y debate sobre la obligatoriedad del voto en Chile". En El genoma electoral chileno, eds. Patricio Navia, Mauricio Morales y Renato Briceño, 55-76. Santiago: Ed. Universidad Diego Portales.

Salvat, Pablo. 1992. "Notas sobre la formación política de los jóvenes: desafíos y esperanzas". En Formación Cívico-Política de la juventud, desafío a la democracia, eds. Cristián Parker y Pablo Salvat, 154-161. Santiago: Ornitorrinco.

Sierra, Lucas. 2007. "El voto como derecho: Una cuestión de principios". En Modernización del régimen electoral chileno, eds. Arturo Fontaine, Cristián Larroulet, José Antonio Viera-Gallo e Ignacio Walker, 157-181. Santiago: PNUD/CIEPLAN.

Thezá, Marcel. 2011. “Jóvenes, participación y ciudadanía: ¿Qué investigar?”. Revista Observatorio de Juventud 29 (Julio): 55-68.

Toro, Sergio. 2007. “La inscripción electoral de los jóvenes en Chile. Factores de incidencia y aproximaciones al debate". En Modernización del régimen electoral chileno, eds. Arturo Fontaine, Cristián Larroulet, José Antonio Viera-Gallo y Ignacio Walker, 101-122. Santiago: CIEPLAN.

Toro, Sergio. 2008. "De lo épico a lo cotidiano: Jóvenes y generaciones políticas en Chile". Revista de ciencia politica 28 (3): 143-160.

Uhlaner, Carole J. 1989. "Rational Turnout: The Neglected Role of Groups". American Journal of Political Science 33 (2): 390-422.

Uhlaner, Carole J. 1995. "What the Downsian Voter Weighs: A Reassessment of the Costs and Benefits of Action". En Information, Participation and Choice: An Economic Theory of Democracy in Perspective, ed. Bernand Grofman, 67-79. Ann Arbor: Michigan University Press.

Valenzuela, J. Samuel. 1985. Democratización vía reforma. La expansión del sufragio en Chile (1863-1868). Buenos Aires: IDES.

Valenzuela, J. S. (1998). "La ley electoral de 1890 y la democratización del régimen político chileno". Estudios Públicos 71 (Invierno): 266-296.

Von Baer, Ena. 2009. "Voto voluntario es igual a más democracia". El Mercurio 27 de enero.

Walker, Patricio. 2010. "El voto voluntario II". El Mercurio, 16 de noviembre.

Wolfinger, Raymond E, y Steven J Rosenstone. 1980. Who Votes? New Haven: Yale University Press.

Gonzalo Contreras es cientista político. Investigador asociado Observatorio Político Electoral, Universidad Diego Portales. E-mail: gonzalo.contreras.ag@gmail.com

Patricio Navia es cientista político, profesor titular de ciencia política, Universidad Diego Portales; Master Teacher of Liberal Studies, New York University. E-mail: patricio.navia@udp.cl 
